\title{
The management of subclinical wart virus infection of the cervix in a genitourinary clinic
}

\author{
K E Rogstad, C A Dixon, I H Ahmed
}

\begin{abstract}
Objective-To assess whether cold coagulation to the cervix eliminates subclinical wart virus infection and to determine the effectiveness of treatment for CIN I and II, using cold coagulation, by genitourinary physicians.

Design-Prospective study.

Setting-Department of Genitourinary medicine in a large teaching hospital.

Participants-All patients who received cold coagulation to the cervix in a 1 year period, who had not had previous treatment.

Results-261 patients were enrolled into this study; of these, 138 (53\%) patients attended for repeat colposcopy and cytology at one year. Cure rates for lesions were $66 \%$ for initial wart virus infection, $80 \%$ for CIN I and $94 \%$ for CIN II and III. Four (5\%) cases in whom repeat cytology was normal had CIN which would have been missed if repeat colposcopy had not been performed at one year.

Conclusions-Cold coagulation is inappropriate treatment for subclinical wart virus infection of the cervix but is useful for the management of patients with CIN. Repeat colposcopy following treatment to the cervix is not necessary if cervical cytology is normal.
\end{abstract}

(Genitourin Med 1992;68:307-308)

\section{Introduction}

Over the last decade, departments of genitourinary (GU) medicine in England have reported rapidly increasing numbers of patients with HPV, rising from 28000 in 1980 to 77000 in $1990 .^{1}$ Evidence is accumulating that links HPV to carcinoma of the cervix ${ }^{2}$ but the natural history of subclinical HPV is not fully known. Because of worries regarding risk of progression to carcinoma, the desire of a patient to have a "normal" smear and the mobile nature of their population, some genitourinary physicians have advocated that patients with subclinical HPV infection of the cervix should receive treatment. A recent survey of GU departments has revealed that, of those offering a colposcopy service, $22 \%$ treat subclinical HPV infection (Dr O Williams, personal communication) despite little evidence as to the effectiveness of such treatment.

A prospective study was therefore initiated to determine the usefulness of cold coagulation in this condition. At the time of the study, colposcopy was performed on all patients with wart virus infection (WVI) (cytology showing two of the following three criteria: multinucleation, dyskaryosis or koilocytosis; or koilocytosis alone if classical) or dyskaryosis on cervical cytology, and on any patient with a visible cervical abnormality.

\section{Methods}

All patients who were colposcoped between 1 October 1988 and 31 September 1989 and who were found to have wart virus infection of the cervix, CIN I or II were offered cold coagulation therapy. Patients who were pregnant or who had had previous treatment to the cervix were excluded from the study. Patients with CIN III lesions and those with lesions extending into the canal or in whom histology was not thought to be representative were referred to a gynaecologist. Treatment was given by one of four GU physicians using a Semm coagulator (Rocket), 4-5 applications at $100^{\circ} \mathrm{C}$, each of 20 seconds duration. The patients were reviewed at 6 weeks to assess the healing of the cervix and repeat cytology was performed at 6 months and 12 months. Repeat colposcopy was offered at 1 year post treatment. Those who did not attend had their addresses checked and were offered 2 further colposcopy appointments.

\section{Results}

During the study period 338 patients were colposcoped. The diagnoses are shown in table 1. Forty one patients were referred to a gynaecologist because of inadequate colposcopy, patient preference or CIN III. Cold coagulation was performed for wart virus infection (201 patients), CIN I (32) and CIN II (27). In addition, one patient with CIN III refused referral and was therefore also treated with cold coagulation.

At 6 months, one patient had severe dyskaryosis on cytology and was referred to a gynaecologist and excluded from further analysis. Therefore, at 1 year 260 patients were recalled for repeat colposcopy and 138 atten-

Table 1 Initial colposcopy $(n=338)$

\begin{tabular}{lc}
\hline Histology & number \\
\hline Normal & 33 \\
Wart virus infection & 209 \\
CIN I & 39 \\
CIN II & 28 \\
CIN III & 26 \\
Unavailable & 3 \\
\hline
\end{tabular}

I H Ahmed

Address correspondence to: Dr K E Rogstad Accepted for publication 24 April 1992 
Table 2 Histology at 1 year post cold coagulation

\begin{tabular}{llll}
\hline & \multicolumn{2}{l}{ Initial histology } \\
\cline { 2 - 4 } & WVI & CIN I & CIN II \& III \\
Histology at repeat & & & \\
Colposcopy & $n=102$ & $n=20$ & $n=16$ \\
\hline Normal & $67(66 \%)$ & $9(45 \%)$ & $7(44 \%)$ \\
Wart virus infection & $31(30 \%)$ & $7(35 \%)$ & $8(50 \%)$ \\
CIN I & $2(2 \%)$ & $3(15 \%)$ & $1(6 \%)$ \\
CIN II & $2(2 \%)$ & $1(5 \%)$ & 0 \\
\hline
\end{tabular}

ded between 12 and 18 months after cold coagulation. The results are shown in table 2 . Of those 102 patients whose initial diagnosis was WVI, 31 (30\%) had persisting WVI, 2 (2\%) were found to have CIN I, and $2(2 \%)$ had CIN II.

Of the 20 patients whose initial diagnosis was CIN I, three (15\%) had persistent CIN I and one $(5 \%)$ had progressed to CIN II. No patient with CIN II or III had persistence or progression of their lesions. Overall cure rates were $66 \%$ for WVI, $80 \%$ for CIN I and $94 \%$ for CIN II and III $\left(x^{2}=6 \cdot 2 p=0.0448\right)$.

Cytology compared with histology at 1 year post treatment is shown in table 3. Only two $(1.5 \%)$ cases of CIN II would have been missed if cytology alone had been performed.

\section{Discussion}

A recent editorial in the $B M J$ has highlighted the lack of solid scientific evidence supporting many medical interventions. ${ }^{3}$ Although there is significant use of cold coagulation in departments of GU Medicine, there have been few published studies showing its effectiveness. Our study reveals that HPV is eliminated in only $66 \%$ of cases. As the failure rate is so high in a condition which is so prevalent and in which the natural history is unclear and where treatment is painful and may affect future fertility and labour, we advocate that cold coagulation should no longer be used. Further work needs to be done to determine whether persistent HPV infection is due to treatment failure or reinfection from other areas of the genital tract or by a sexual partner. A con-

Table 3 Cytology compared with histology at 1 year

\begin{tabular}{llllll}
\hline & \multicolumn{3}{l}{ Histology } & & \\
\cline { 2 - 6 } Cytology & Normal & WVI & CIN I & CIN II & CIN III \\
\hline Normal & 80 & 29 & 3 & 1 & 0 \\
Wart virus infection & 2 & 15 & 3 & 1 & 0 \\
Mild warty dyskaryosis & 0 & 2 & 0 & 0 & 0 \\
Moderate warty dyskaryosis & 1 & 0 & 0 & 1 & 0 \\
Severe warty dyskaryosis & 0 & 0 & 0 & 0 & 0 \\
\hline
\end{tabular}

trolled trial would help to determine more accurately the effectiveness of cold coagulation in this condition, but until the natural history of subclinical HPV of the cervix is known routine treatment should be withheld.

The cure rates obtained for CIN in our study were equivalent to those obtained by Smart et $\mathrm{al}^{4}$ ( $90 \%$ for CIN II and III) but lower than those of Cassidy et $a l^{5}$ (94-97\% for all CIN). This could be due to several factors, including method of follow-up and a different population group being studied. Our finding of a low incidence of significant lesions, which would have been missed if colposcopy had not been performed at 1 year following treatment, agree with other studies, ${ }^{6} 7$ which advocate only cytological follow-up.

This study shows that colposcopy and subsequent treatment with cold coagulation can be carried out in a department of GU medicine, thus reducing the pressure on already stressed gynaecological services. Patients will benefit by being treated in an environment of which they already have experience and by the team of doctors and nurses in whom they have developed confidence and trust. It should not be forgotten that these procedures can cause anxiety and stress ${ }^{89}$ and physicians must therefore ensure that patients are not subjected to unnecessary investigation and treatment.

It is essential that there is close co-operation between GU physicians, gynaecologists and histopathologists and that regular audit is performed to ensure that standards are maintained.

In conclusion, subclinical HPV infection of the cervix should not be treated with cold coagulation but low grade CIN can be adequately treated with it in a department of genitourinary medicine.

1 Department of Health: New Cases seen at Genitourinary Medicine Clinics in England 1990/91 SM 12B.

2 Editorial Viruses and cervical cancer $B M F$ 1991;302 251-2.

3 Smith R. Editorial. Where is the wisdom? The poverty of medical evidence. $B M \mathcal{F}$ 1991;303:798-9.

4 Smart GE, Livingstone JRB, Gordon A, et al. Randomized trial to compare laser with cold coagulation therapy in the treatment of CIN II and III. (Abstract) Colposcopy and Gynaecologic Laser Surgery 1987;3:47.

5 Cassidy LJ, Mathers A, Kennedy JH. Cold coagulation revisited. (Abstract) Colposcopy and Gynaecologic Laser Surgery 1987;3:232

6 Lopes A, Mor-Yosef S, Pearson S, Ireland D, Monaghan J $M$. Is routine colposcopy assessment necessary following laser ablation of cervical intraepithelial neoplasia? $\mathrm{Br} \mathscr{J}$ Obstet Gynaecol 1990;97:175-7.

7 Giles J, Lim J, Deery A, Walker P. Medical audit in the follow-up of patients treated for cervical intraepithelia neoplasia. f Obstet Gynaecol 1989;10:78-79.

8 Marteau TM, Walker P, Giles J, Smail M. Anxieties in women undergoing colposcopy. $\mathrm{Br} \mathcal{f}$ Obstet Gynaecol 1990;97:859-61.

9 Boag FC, Dillon AM, Catalan J, Edwards R, Barton SE Assessment of psychiatric morbidity in patients attending a colposcopy clinic situated in a genitourinary medicine clinic. Genitourin Med 1991;67:481-6. 